\title{
Exigência de Metionina + Cistina para Frangos de Corte na Fase de Crescimento e Acabamento 1
}

\author{
Ramalho José Barbosa Rodrigueiro², Luiz Fernando Teixeira Albino ${ }^{3}$, Horacio Santiago \\ Rostagno ${ }^{3}$, Paulo Cezar Gomes ${ }^{3}$, Paulo Cezar Pozza ${ }^{4}$, Rafael Neme ${ }^{5}$
}

\begin{abstract}
RESUMO - Com o objetivo de determinar as exigências de metionina+cistina, foram utilizados 1440 e 1080 frangos de corte da marca comercial Hubbard, $50 \%$ de cada sexo, para as fases de crescimento e acabamento, respectivamente. Seis níveis de suplementação de DL-metionina $(0,0 ; 0,06,0,12 ; 0,18 ; 0,24 ; \mathrm{e} 0,30 \%)$ foram adicionados às rações basais deficientes em metionina+cistina. Foram avaliados, aos 22-42 e 43-56 dias, ganho de peso, consumo de ração, conversão alimentar, rendimento e composição química da carcaça, gordura abdominal e concentração plasmática de ácido úrico. Com base nas análises estatística e nos parâmetros estudados durante a fase de crescimento ( 22 a 42 dias de idade), sugere-se utilizar 0,896 e $0,856 \%$ de metionina+cistina total para machos e fêmeas, respectivamente. Para a fase de acabamento ( 43 a 56 dias de idade), com base nas análises estatísticas e nos parâmetros estudados, sugere-se utilizar 0,764 e $0,740 \%$ de metionina+cistina total para machos e fêmeas, respectivamente.
\end{abstract}

Palavras-chave: composição da carcaça, desempenho, exigência de metionina+cistina, frangos de corte, rendimento de carcaça

\section{Methionine+Cystine Requirement for Broilers at the Growing and Finishing Phases}

\begin{abstract}
With the objective to determine the methionine+cystine requirements, 1440 and 1080 commercial Hubbard broilers were used, $50 \%$ of each sex at the growing and finishing phases, respectively. Six supplemental levels of DL-methionine (.0, .06, .12, $.18, .24$, and $.30 \%$ ) were added to methionine+cystine deficient basal diets. Body weight gain, feed intake, feed:gain ratio, carcass yield and composition, abdominal fat and plasma uric acid concentration were evaluated from 22-42 and 43-56 days of age. Based on the statistical analysis of the studied parameters during the growing phase (22 to 42 days of age), it is suggested to use .896 and $.856 \%$ of total methionine+cystine for males and females, respectively. For the finishing phase (43 to 56 days of age), based in the statistic analysis and in the studied parameters, it is suggested to use $.764 \%$ and $.740 \%$ of total methionine+cystine for males and females, respectively.
\end{abstract}

Key Words: broilers, carcass yield, composition carcass, performance, sulfur amino acids requirements,

\section{Introdução}

Para o próximo milênio, segundo CARTE(1993), o frango de corte apresentará ganho de $70 \mathrm{~g}$ no peso vivo e redução de $20 \mathrm{~g}$ no consumo de ração por $\mathrm{kg}$ de peso vivo. Apresentará idade de abate aos 41 dias de idade, com peso vivo de 2240 g, e conversão alimentar de 1,78 (AVES e OVOS, 1995). Além disso, as exigências atuais de mercado têm causado profundas alterações nas características das aves de corte. O aumento da comercialização de aves em partes, em detrimento da carcaça, e o processamento industrial têm resultado na crescente especialização, ou seja, as empresas procuram adquirir marcas comerciais de frangos de corte com maior porcentagem de coxa e peito e menor teor de gordura. Desse modo, torna-se evidente a necessidade constante em esta- belecer as exigências nutricionais para frangos de corte, para que as aves utilizem adequadamente os nutrientes, principalmente, na fase de crescimento e acabamento, em virtude de o consumo de ração, nesse período, ser mais pronunciado. Essa necessidade é reforçada pelo número reduzido de trabalhos no Brasil com aminoácidos (SCHERMANN e BELLAVER, 1995). Anteriormente, as publicações eram motivadas pelo avanço na produção de aminoácidos sintéticos, principalmente metionina e lisina, os quais eram considerados os mais limitantes nas rações à base de milho e farelo de soja, que se tornaram disponíveis no mercado a preços acessíveis (HAN et al., 1992).

Para mostrar a importância dos fatos supracitados, foi realizado um Simpósio Internacional na Universidade Federal de Viçosa (UFV), especificamente

\footnotetext{
${ }^{1}$ Parte da Dissertação apresentada pelo primeiro autor à Universidade Federal de Viçosa para obtenção do título de "Magister Scientiae".

2 Zootecnista. Estudante de Pós-Graduação, UFV - 36571-000 - Viçosa, MG. Bolsista do CNPq e da FAPEMIG.

${ }^{3}$ Professor do Departamento de Zootecnia, UFV - 36571-000 - Viçosa, MG.

${ }^{4}$ Professor do Departamento de Zootecnia, UNIOESTE - 85960-000 - Mal. Cândido Rondon - PR.

5 Estudante de Doutorado FCAV/UNESP - Jaboticabal, SP.
} 
sobre as exigências nutricionais de aves e suínos, discutindo a necessidade de constante de pesquisas, quanto ao estabelecimento de exigências nutricionais para frangos de corte. Os trabalhos apresentados sobre exigências em aminoácidos sulfurosos, para frangos de corte, apresentam resultados contraditórios. Parte substancial dessa inconsistência é atribuída ao uso de rações basais que apresentam redução ou não no nível de proteína das aves, associada ao uso de suplementação de D-L metionina e, ou, cistina sintética como única fonte de aminoácidos sulfurosos.

Com base nesses fatos, torna-se evidente a necessidade de estabelecer as exigências de metionina+cistina para frangos de corte nas fases de crescimento e acabamento.

\section{Material e Métodos}

A pesquisa foi conduzida nas instalações do Setor de Avicultura do Departamento de Zootecnia da Universidade Federal de Viçosa. Foram utilizados 1440 frangos (Hubbard) no período de crescimento (Experimento I) e 1080 frangos (Hubbard) no período de acabamento (Experimento II), sendo 50\% de cada sexo para as duas fases. Devido a problemas de manejo, o peso vivo dos frangos de corte com 21 dias de idade foi de 529 e $530 \mathrm{~g}$, e, aos 42 dias de idade, 1964 e 1667 g, para machos e fêmeas, respectivamente. Como o período de acabamento dos frangos de corte em condições comerciais é de aproximadamente seis dias, houve a necessidade de estender o período experimental para 14 dias, a fim de verificar o efeito dos tratamentos às aves; desse modo, as aves do Experimento II foram criadas até 56 dias de idade.

As aves foram alojadas, num galpão convencional para frangos de corte, em 72 boxes. O programa de luz adotado foi o contínuo ( 24 horas de luz natural + artificial), durante todo o período experimental. Foi utilizada a maravalha como cama e o fornecimento de ração e água foi à vontade.

As temperaturas observadas no interior do galpão, durante todo o período experimental, estão apresentadas na Tabela 1.

As aves foram submetidas à ração basal (Tabela 2) contendo $19,50 \%$ PB e $3150 \mathrm{kcal} \mathrm{EM} / \mathrm{kg}$, na fase de crescimento (22 a 42 dias de idade), e $17,00 \%$ PB e $3200 \mathrm{kcal} \mathrm{EM} / \mathrm{kg}$ na fase de acabamento (43 a 56 dias de idade), suplementada com seis níveis de DLmetionina $98 \%(0,00 ; 0,06 ; 0,12 ; 0,18 ; 0,24 ; \mathrm{e} 0,30 \%)$, resultando em um total de 0,$630 ; 0,690 ; 0,750 ; 0,810$; 0,870 ; e $0,930 \%$ de metionina+cistina e 0,$560 ; 0,620$;
0,$680 ; 0,740 ; 0,800 ; \mathrm{e} 0,860 \%$ de metionina + cistina, para a fase de crescimento e acabamento, respectivamente.

As rações experimentais foram isocalóricas. Os níveis nutricionais, exceto os de metionina+cistina, foram atendidos segundo as recomendações de ROSTAGNO et al. (1996). As suplementações com DL-metionina foram feitas em substituição ao amido de milho, ficando, dessa forma, todas as rações isoprotéicas. As aves, antes de entrarem em cada período experimental, foram alimentadas com ração à base de milho e farelo de soja, atendendo as recomendações de ROSTAGNO et al. (1996). No $42^{\circ}$ e $56^{\circ}$ dia de idade das aves, ganho de peso, consumo de ração, conversão alimentar, rendimento e composição química da carcaça e concentração de ácido úrico no plasma foram avaliados.

Foi utilizado o delineamento inteiramente casualizado, em arranjo fatorial 2 x 6 (dois sexo x seis suplementação de D L-metionina), com seis repetições de 20 e 15 aves por unidade experimental, para o período de crescimento (experimento I) e acabamento (experimento II), respectivamente.

As análises estatísticas das características estudadas foram realizadas de acordo com o programa SAEG desenvolvido pela UNIVERSIDADE FEDERAL DE VIÇOSA (1997). A estimativa das exigências de metionina+cistina foi estabelecida por meio dos modelos de regressão.

\section{Resultados e Discussão}

Efeito dos níveis de metionina+cistina (Met+Cis) da ração sobre o desempenho dos frangos de corte no período de 22 a 42 dias de idade

Os resultados de desempenho obtidos no período de crescimento (22 a 42 dias de idade), em função dos níveis de Met+Cis da ração, estão apresentados na Tabela 3.

Ganho de peso e consumo de ração

$\mathrm{O}$ aumento dos níveis de Met+Cis da ração apresentaram, no ganho de peso, efeito quadrático $(\mathrm{P} \leq 0,05)$ e linear $(\mathrm{P} \leq 0,05)$, respectivamente, para machos e fêmeas. O consumo de ração foi influenciado $(\mathrm{P} \leq 0,05)$ de forma linear para ambos os sexos, diminuindo à medida que se elevou o nível de Met+Cis na ração. Estes resultados estão de acordo com WHEELER e LATSHAW (1981), os quais relatam que o aumento do nível de Met+Cis na ração favorece o aumento do peso corporal e a diminuição do consumo de ração. $\mathrm{O}$ maior consumo da ração basal (mais deficiente em 
Tabela 1 - Temperatura do ar no interior do galpão durante o período de 22 a 56 dias de idade das aves

Table 1 - Temperature of the air inside avian house from 22 to 56 days of age

\begin{tabular}{|c|c|c|}
\hline \multirow{3}{*}{$\begin{array}{l}\text { Idade das aves (dias) } \\
\text { Age of birds (days) }\end{array}$} & \multicolumn{2}{|c|}{$\begin{array}{c}\text { Temperatura do } \operatorname{ar}\left({ }^{\circ} \mathrm{C}\right) \\
\text { Temperature of the air }\end{array}$} \\
\hline & Máxima média & Mínima média \\
\hline & Mean maximum & Mean minimum \\
\hline $22-28$ & $28,14 \pm 2,48$ & $20,43 \pm 1,13$ \\
\hline $29-35$ & $26,14 \pm 1,95$ & $16,00 \pm 2,08$ \\
\hline $36-42$ & $26,25 \pm 2,63$ & $17,50 \pm 1,29$ \\
\hline $43-49$ & $27,60 \pm 1,52$ & $18,60 \pm 1,14$ \\
\hline $50-56$ & $27,40 \pm 2,79$ & $18,80 \pm 2,05$ \\
\hline
\end{tabular}

Met+Cis) está de acordo com SEKIS et al. (1975) e CAREN e HILL (1961). Resultados contraditórios foram encontrados por SILVA (1996), utilizando diferentes níveis de Met+Cis em rações com 20\% PB e $3100 \mathrm{kcal} \mathrm{EM} / \mathrm{kg}$.

Como as rações fornecidas neste experimento foram isoenergéticas e isoprotéicas, à base de milho e farelo de soja, o menor ganho de peso das aves, associado ao maior consumo da ração basal, demonstra que o aminoácido limitante na ração diminui a síntese de proteína corporal. Estas observações

Tabela 2 - Composição percentual da ração basal no período de crescimento (I) e acabamento (II)

Table 2 - Percentage composition of basal diets for the period of growing (I) and final (II)

\begin{tabular}{|c|c|c|}
\hline $\begin{array}{l}\text { Ingrediente } \\
\text { Ingredient }\end{array}$ & $\begin{array}{c}\text { Ração basal I } \\
\text { Basal diet I }\end{array}$ & $\begin{array}{c}\text { Ração basal II } \\
\text { Basal diet II }\end{array}$ \\
\hline Milho (Corn) & 61,140 & 65,540 \\
\hline Amido (Corn starch) & 0,320 & 3,170 \\
\hline Farelo de soja (Soybean meal) & 31,200 & 24,670 \\
\hline Óleo de soja (Soybean oil) & 3,800 & 3,190 \\
\hline Calcário (Limestone) & 0,930 & 1,030 \\
\hline Fosfato bicálcico (Dicalcium phosphate) & 1,800 & 1,660 \\
\hline Mistura mineral $^{1}$ (Mineral premix) & 0,050 & 0,050 \\
\hline Mistura vitamínica $^{2}$ (Vitamin premix) & 0,100 & 0,100 \\
\hline Sal comum $($ Salt $)$ & 0,350 & 0,350 \\
\hline BHT & 0,020 & 0,020 \\
\hline Anticoccidiano (Coccidiostatic) & 0,100 & - \\
\hline CL-Colina (Choline chlorine), $60 \%$ & 0,100 & 0,060 \\
\hline Bacitracina de $\mathrm{Zn}$ (Zinc bacitracin) & 0,010 & - \\
\hline L-lisina HCL (Lysine), $78 \%$ & 0,080 & 0,180 \\
\hline DL-metionina (Methionine), $98 \%$ & - & - \\
\hline \multicolumn{3}{|l|}{ Valores calculados } \\
\hline \multicolumn{3}{|l|}{ Calculated composition } \\
\hline Proteína bruta (Crude protein), \% & 19,50 & 17,00 \\
\hline $\mathrm{EM}(M E), \mathrm{kcal} / \mathrm{kg}$ & 3150 & 3200 \\
\hline $\mathrm{Na}, \%$ & 0,174 & 0,175 \\
\hline $\mathrm{Ca}, \%$ & 0,897 & 0,880 \\
\hline $\mathrm{P}$ disponível (Available P), \% & 0,444 & 0,410 \\
\hline Metionina (Methionine), \% & 0,346 & 0,272 \\
\hline Metionina+cistina (Methionine + cystine), $\%$ & 0,630 & 0,560 \\
\hline Lisina (Lysine), \% & 1,099 & 1,000 \\
\hline Triptofano (Tryptofan), \% & 0,258 & 0,218 \\
\hline Treonina (Threonine), \% & 0,763 & 0,662 \\
\hline \multicolumn{3}{|c|}{$\begin{array}{l}1 \text { Níveis de garantia por quilo de produto: } \mathrm{Mn}, 106,0 \mathrm{~g} ; \mathrm{Fe}, 100,0 \mathrm{~g} ; \mathrm{Cu}, 20,0 \mathrm{~g} ; \mathrm{Co}, 2,0 \mathrm{~g} ; \mathrm{I} \text {, } \\
2,0 \mathrm{~g} \text {; e veículo qsp, } 1000 \mathrm{~g} \text {. } \\
2 \text { por quilo de produto: vit. A, } 10.000 .000 \mathrm{Ul} \text {; vit } \mathrm{D}_{3}, 2.000 .000 \mathrm{Ul} \text {; vit E, } 30.000 \mathrm{Ul} \text {; vit } \mathrm{B}_{1}, 2,0 \mathrm{~g} \text {; } \\
\text { vit } \mathrm{B}_{6}, 3,0 \mathrm{~g} \text {; Ac. Pantotênico (Panthotenic acid), } 12,0 \mathrm{~g} \text {; Biotina (Biotin), } 0,10 \mathrm{~g} \text { vitamina } \mathrm{K}_{3} \text {, } \\
3,0 \mathrm{~g} \text {; Ácido fólico (Folic acia), } 1,0 \mathrm{~g} \text {; Ácido nicotínico (Nicotinic acid), } 50,0 \mathrm{~g} \text {; Bacitracina de } \\
\text { zinco (Zinc bacitracin), } 10,0 \mathrm{~g} \text {; BHT } 5,0 \mathrm{~g} \text {; vitamina } \mathrm{B}_{12}, 15.000 \mathrm{mcg} \text {; Se, } 0,25 \mathrm{~g} \text {; e } \\
\text { veículo q.s.p. } 1000 \mathrm{~g} \text {. }\end{array}$} \\
\hline
\end{tabular}


Tabela 3 - Desempenho de frangos de corte submetidos a diferentes níveis de metionina+cistina de 22 a 42 dias Table 3 - Performance of broilers submitted to different methionine + cystine levels from 22 to 42 days

\begin{tabular}{|c|c|c|c|c|c|c|}
\hline \multirow{2}{*}{$\begin{array}{l}\text { Metionina+Cistina }(\%) \\
\text { Methionine }+ \text { Cystine }\end{array}$} & \multicolumn{2}{|c|}{$\begin{array}{l}\text { Ganho de peso }(\mathrm{g}) \\
\text { Body weight gain }\end{array}$} & \multicolumn{2}{|c|}{$\begin{array}{c}\text { Consumo de ração }(\mathrm{g}) \\
\text { Feed intake }\end{array}$} & \multicolumn{2}{|c|}{$\begin{array}{c}\text { Conversão alimentar }(\mathrm{g} / \mathrm{g}) \\
\text { Feed:gain ratio }\end{array}$} \\
\hline & $\begin{array}{l}\text { Macho } \\
\text { Male }\end{array}$ & $\begin{array}{l}\text { Fêmea } \\
\text { Female }\end{array}$ & $\begin{array}{c}\text { Macho } \\
\text { Male }\end{array}$ & $\begin{array}{l}\text { Fêmea } \\
\text { Female }\end{array}$ & $\begin{array}{c}\text { Machos } \\
\text { Male }\end{array}$ & $\begin{array}{l}\text { Fêmeas } \\
\text { Female }\end{array}$ \\
\hline 0,630 & $1.349,33$ & $1.204,33$ & $3.281,17$ & $2.848,75$ & 2,329 & 2,366 \\
\hline 0,690 & $1.489,33$ & $1.246,58$ & $3.121,92$ & $2.628,58$ & 2,132 & 2,167 \\
\hline 0,750 & $1.547,25$ & $1.272,00$ & $3.218,58$ & $2.727,92$ & 2,082 & 2,145 \\
\hline 0,810 & $1.542,83$ & $1.276,17$ & $3.115,67$ & $2.619,75$ & 2,190 & 2,054 \\
\hline 0,870 & $1.609,50$ & $1.297,83$ & $3.112,17$ & $2.684,33$ & 1,933 & 2,068 \\
\hline 0,930 & $1.590,42$ & $1.291,25$ & $3.045,08$ & $2.676,25$ & 1,915 & 2,073 \\
\hline Met+Cis (\%) & $\mathrm{Q}$ & $\mathrm{L}$ & $\mathrm{L}$ & $\mathrm{L}$ & $\mathrm{Q}$ & $\mathrm{Q}$ \\
\hline Exigência estimada & 0,879 & - & - & - & 0,896 & 0,856 \\
\hline $\begin{array}{l}\text { Estimated requirement } \\
\text { Médias dos sexos }\end{array}$ & $1.521,44^{\mathrm{a}}$ & $1.264,69^{\mathrm{b}}$ & $3.149,10^{\mathrm{a}}$ & $2.697,60^{\mathrm{b}}$ & $2,097^{\mathrm{b}}$ & $2,145^{\mathrm{a}}$ \\
\hline $\begin{array}{l}\text { Sexmean } \\
\text { CV }(\%)\end{array}$ & \multicolumn{2}{|c|}{3,62} & \multicolumn{2}{|c|}{4,88} & \multicolumn{2}{|c|}{4,18} \\
\hline
\end{tabular}

Médias seguida de letras distintas, dentro de cada linha, para sexo, diferem pelo teste $F(P \leq 0,05)$.

$Q$ - Efeito quadrático do nível de Met+Cis pelo teste $F(P \leq 0,05)$.

$L$ - Efeito linear do nível de Met+Cis pelo teste $F(P \leq 0,05)$.

Means followed by different letters, within a row, for sex, are different by $F$ test $(P \leq .05)$.

Quadratic effect of the Meth + Cys level by $F$ test $(P \leq .05)$.

Linear effect of Meth+Cys level by $F$ test $(P \leq .05)$.

comprovam, portanto, a lei do mínimo na nutrição animal e, também, o fato de que o consumo de ração pelas aves não é dependente exclusivamente da teoria glicostática, mas também é influenciado pelos níveis de aminoácidos essenciais da ração.

As estimativas de exigência de Met+Cis para machos e fêmeas foram feitas a partir de equações ajustadas por meio dos modelos de regressão polinomial, que se encontram na Tabela 6 .

Os níveis de Met+Cis causaram efeito quadrático $(\mathrm{P} \leq 0,05)$ no ganho de peso de machos, estimando a exigência em $0,879 \%$. Resultado superior foi encontrado por SILVA (1996) e SCHUTTE e PACK (1995a).

As fêmeas apresentaram efeito linear significativo para ganho de peso, sugerindo mínimo de 0,930\%, ou seja, o maior valor de Met+Cis utilizado neste experimento, mostrando que os níveis utilizados não foram suficientes para determinar ponto de máximo para as fêmeas, indicando maior exigência de Met+Cis para esse sexo. Isso, provavelmente, se deve à maior velocidade de empenamento das fêmeas em relação aos machos, necessitando, portanto, de maiores teores de cistina, os quais podem ser adquiridos da metionina pela conversão metabólica. AJANG et al. (1993), PESTI et al. (1996) e Bordas, citado por COLNAGO (1996), sugerem que a velocidade de empenamento pode influenciar a exigência de proteína e aminoácidos sulfurosos. Existe, entretanto, a possibilidade de adotar $0,870 \%$ de Met+Cis, por se apresentar como melhor valor biológico diante da variável em questão.

\section{Conversão alimentar}

Os níveis de Met+Cis influenciaram de forma quadrática a conversão alimentar para ambos os sexos. Como era de se esperar, as fêmeas apresentaram pior conversão alimentar que os machos. As estimativas de exigências de Met+Cis, feitas a partir de equações ajustadas por meio de modelos de regressão para ambos os sexos, podem ser observadas na Tabela 6.

As exigências estimadas para conversão alimentar foram de 0,896 e $0,856 \%$ de Met+Cis para machos e fêmeas, respectivamente. SCHUTTE e PACK (1995b) estimaram o mínimo de $0,880 \%$ de Met+Cis, em função da conversão alimentar.

Efeito dos níveis de metionina+cistina (Met+Cis) sobre rendimento de carcaça eviscerada e gordura abdominal de frangos de corte aos 42 dias de idade

Os resultados de rendimento de carcaça eviscerada e gordura abdominal aos 42 dias de idade, em função dos níveis de Met+Cis na ração, estão apresentados na Tabela 4.

\section{Machos}

$\mathrm{O}$ rendimento das pernas não foi influenciado $(\mathrm{P} \geq 0,05)$ pelos níveis de Met+Cis, apresentando apenas efeito de sexo, em que os machos foram superiores às fêmeas, não ocorrendo o mesmo com os 
Rev. bras. zootec.

Tabela 4 - Efeito de diferentes níveis de Met+Cis da ração sobre rendimento de carcaça eviscerada, cortes e gordura abdominal de frangos de corte aos 42 dias de idade

Table 4 - Effect of different leve of Meth+Cys of the diet on eviscerated carcass, yield parts and abdominal fat of broilers from 42 days of age

\begin{tabular}{|c|c|c|c|c|c|c|c|c|c|c|}
\hline \multirow[b]{3}{*}{$\begin{array}{l}\text { Met+Cis }(\%) \\
\text { Meth }+ \text { Cys }\end{array}$} & \multicolumn{10}{|c|}{ Rendimento(Yield), \% } \\
\hline & \multicolumn{2}{|c|}{$\begin{array}{l}\text { Carcaça } \\
\text { Carcass } \\
\end{array}$} & \multicolumn{2}{|c|}{$\begin{array}{l}\text { Peito } \\
\text { Breast } \\
\end{array}$} & \multicolumn{2}{|c|}{$\begin{array}{c}\text { Filé de peito } \\
\text { Breastfillet }\end{array}$} & \multicolumn{2}{|c|}{$\begin{array}{c}\text { Pernas } \\
\text { Legs }\end{array}$} & \multicolumn{2}{|c|}{$\begin{array}{c}\text { Gordura } \\
\text { Fat }\end{array}$} \\
\hline & $\begin{array}{c}\text { Macho } \\
\text { Male }\end{array}$ & $\begin{array}{l}\text { Fêmea } \\
\text { Female }\end{array}$ & $\begin{array}{c}\text { Macho } \\
\text { Male }\end{array}$ & $\begin{array}{l}\text { Fêmea } \\
\text { Female }\end{array}$ & $\begin{array}{l}\text { Macho } \\
\text { Male }\end{array}$ & $\begin{array}{l}\text { Fêmea } \\
\text { Female }\end{array}$ & $\begin{array}{l}\text { Macho } \\
\text { Male }\end{array}$ & $\begin{array}{l}\text { Fêmea } \\
\text { Female }\end{array}$ & $\begin{array}{c}\text { Macho } \\
\text { Male }\end{array}$ & $\begin{array}{l}\text { Fêmea } \\
\text { Female } \\
\end{array}$ \\
\hline 0,630 & 62,50 & 63,66 & 28,61 & 29,80 & 18,75 & 19,38 & 31,09 & 30,08 & 2,584 & 2,564 \\
\hline 0,690 & 64,79 & 64,74 & 30,34 & 30,63 & 20,16 & 19,63 & 30,57 & 29,66 & 2,210 & 2,412 \\
\hline 0,750 & 63,87 & 64,67 & 30,02 & 30,93 & 19,94 & 20,77 & 30,96 & 29,85 & 1,902 & 2,008 \\
\hline 0,810 & 64,26 & 64,93 & 29,95 & 31,08 & 20,26 & 20,74 & 31,10 & 29,56 & 1,891 & 2,086 \\
\hline 0,870 & 63,87 & 64,42 & 29,52 & 30,88 & 19,79 & 21,20 & 30,76 & 29,68 & 1,901 & 2,149 \\
\hline 0,930 & 64,12 & 65,21 & 30,15 & 30,87 & 20,71 & 20,89 & 31,02 & 29,82 & 1,618 & 2,148 \\
\hline$\% \mathrm{Met}+\mathrm{C}$ is & $\mathrm{Q}$ & $\mathrm{L}$ & $\mathrm{Q}$ & $\mathrm{Q}$ & $\mathrm{L}$ & $\mathrm{L}$ & $\mathrm{ns}$ & $\mathrm{ns}$ & $\mathrm{L}$ & $\bar{L}$ \\
\hline Exigência & 0,814 & - & 0,822 & 0,828 & - & - & - & - & - & - \\
\hline $\begin{array}{l}\text { Requirement } \\
\text { Médias }\end{array}$ & $63,91^{\mathrm{b}}$ & $64,61^{\mathrm{a}}$ & $29,77^{b}$ & $30,69^{\mathrm{a}}$ & $19,94^{b}$ & $20,43^{\mathrm{a}}$ & $30,96^{\mathrm{a}}$ & $29,77^{b}$ & $2,016^{\mathrm{b}}$ & $2,228^{\mathrm{a}}$ \\
\hline $\begin{array}{l}\text { Means } \\
\text { CV }(\%)\end{array}$ & \multicolumn{2}{|c|}{1,45} & \multicolumn{2}{|c|}{2,46} & \multicolumn{2}{|c|}{3,87} & \multicolumn{2}{|c|}{2,50} & \multicolumn{2}{|c|}{18,02} \\
\hline
\end{tabular}

Médias seguidas de letras distintas, dentro de cada linha, para sexo, diferem pelo teste $F(P \leq 0,05)$.

$Q$ - Efeito quadrático do nível de Met+Cis pelo teste $F(P \leq 0,05)$.

$L$ - Efeito linear do nível de Met+Cis pelo teste $F(P \leq 0,05)$.

ns Efeito não-significativo pelo teste $F(P \geq 0,05)$.

Means followed by different letters, within a row, for sex, are different by $F$ test $(P \leq .05)$.

Quadratic effect of the Meth+Cys level by $F$ test $(P \leq .05)$.

Linear effect of Meth+Cys level by $F$ test $(P \leq .05)$.

Not significant effect by $F$ test $(P \leq .05)$.

demais cortes. O rendimento de gordura abdominal foi menor $(\mathrm{P} \leq 0,05)$ nos machos, quando comparado ao das fêmeas, no entanto, efeito linear pode ser observado em ambos os sexos. Dessa forma, o maior nível de Met+Cis, 0,930\%, foi considerado como o nível mínimo para menor deposição de gordura abdominal. O mesmo nível pode ser adotado para a variável dependente filé de peito, que apresentou efeito linear, à medida que se aumentou o nível de Met+Cis na ração.

Em razão do efeito quadrático $(\mathrm{P} \leq 0,05)$ obtido para rendimento de carcaça e peito, para machos, em função dos níveis de Met+Cis, a exigência estimada a partir de equações ajustadas por meio dos modelos de regressão foi 0,814 e $0,822 \%$, respectivamente.

\section{Fêmeas}

As fêmeas apresentaram rendimentos superiores de carcaça, peito e filé de peito em relação aos machos. Efeito linear $(\mathrm{P} \leq 0,05)$ foi verificado para rendimento de carcaça, filé de peito e gordura abdominal; nesse sentido, o maior nível de Met+Cis estudado, $0,930 \%$, foi considerado para proporcionar máximo rendimento para as variáveis em questão. $\mathrm{O}$ rendimento de peito, por sua vez, apresentou efeito quadrático $(\mathrm{P} \leq 0,05)$, em função dos níveis de Met+Cis.
Os níveis de Met+Cis não influenciaram o rendimento de perna. Resultados semelhantes foram encontrados por JENSEN et al. (1989), ao observarem diminuição de forma significativa na deposição de gordura abdominal para ambos os sexos, quando as aves foram alimentadas com rações contendo níveis adicionais de metionina. Isso se deve ao fato de a ração com menor nível de Met+Cis proporcionar maior consumo de alimento e, conseqüentemente, maior consumo de energia metabolizável pelo imbalanço de aminoácidos; então, o excesso de energia consumida é convertido em gordura (CAREN e HILL, 1961; SEKIS et al., 1975).

Efeito dos níveis de metionina+cistina (Met+Cis) sobre a composição química da carcaça eviscerada e concentração de ácido úrico no plasma sangüineo de frangos de corte aos 42 dias de idade

A composição química da carcaça eviscerada e concentração de ácido úrico no plasma sangüíneo de frangos de corte, aos 42 dias de idade, em função do nível de Met+Cis, estão apresentados na Tabela 5.

As concentrações de ácido úrico no plasma sangüíneo foram iguais $(P \geq 0,05)$ entre machos $\mathrm{e}$ fêmeas. O elevado coeficiente de variação $(\mathrm{CV})$ correspondente a esta variável mostrou-se inadequa- 
Tabela 5 - Efeito de diferentes níveis de Met+Cis sobre a composição química da carcaça na matéria natural e concentração de ácido úrico em frangos de corte, aos 42 dias de idade ${ }^{1}$

Table 5 - Effect of different Met+Cys levels on the chemical carcass composition in the fresh matter and concentration of uric acid in broilers, from 42 days of age

\begin{tabular}{|c|c|c|c|c|c|}
\hline \multirow[b]{2}{*}{ Met + Cis $($ Meth $+C y s), \%$} & \multicolumn{5}{|c|}{ Macho (Male) } \\
\hline & $\mathrm{AU}$ & UM & MS & PB & $\mathrm{EE}$ \\
\hline 0,630 & 1,922 & 65,23 & 34,77 & 16,52 & 12,10 \\
\hline 0,690 & 2,036 & 66,22 & 33,78 & 16,29 & 14,99 \\
\hline 0,750 & 2,277 & 65,81 & 34,19 & 16,64 & 9,60 \\
\hline 0,810 & 2,134 & 66,35 & 33,64 & 16,90 & 10,94 \\
\hline 0,870 & 2,002 & 67,25 & 32,75 & 16,59 & 8,87 \\
\hline 0,930 & 1,744 & 66,71 & 33,28 & 17,30 & 8,91 \\
\hline \multirow[t]{2}{*}{ Met+Cis $(M e t h+C y s), \%$} & $\mathrm{~ns}$ & $\mathrm{~L}$ & $\mathrm{~L}$ & $\mathrm{~ns}$ & $\mathrm{~L}$ \\
\hline & \multicolumn{5}{|c|}{ Fêmea (Female) } \\
\hline 0,630 & 2,449 & 65,08 & 34,92 & 15,75 & 18,33 \\
\hline 0,690 & 2,191 & 65,30 & 34,70 & 16,99 & 13,32 \\
\hline 0,750 & 2,376 & 65,92 & 34,08 & 16,58 & 11,09 \\
\hline 0,810 & 2,138 & 66,25 & 33,75 & 16,44 & 12,21 \\
\hline 0,870 & 1,695 & 66,01 & 33,99 & 16,25 & 11,16 \\
\hline 0,930 & 2,692 & 65,49 & 34,51 & 16,78 & 12,06 \\
\hline Met+Cis $($ Meth + Cys $), \%$ & $\mathrm{~ns}$ & Ns & $\mathrm{ns}$ & $\mathrm{ns}$ & Q \\
\hline \multicolumn{6}{|l|}{ Exigências estimadas } \\
\hline \multicolumn{6}{|l|}{ Estimated requirements } \\
\hline Macho & - & - & - & - & - \\
\hline \multicolumn{6}{|l|}{ Male } \\
\hline Fêmea & - & - & - & - & 0,831 \\
\hline \multirow{2}{*}{\multicolumn{6}{|c|}{$\begin{array}{l}\text { Females } \\
\text { Médias dos sexos } \\
\text { Sex means }\end{array}$}} \\
\hline & & & \multicolumn{3}{|c|}{ Sex means } \\
\hline Macho & $2,019^{\mathrm{a}}$ & $66,26^{\mathrm{a}}$ & $33,73^{\mathrm{a}}$ & $16,71^{\mathrm{a}}$ & $10,90^{\mathrm{b}}$ \\
\hline \multicolumn{6}{|l|}{ Male } \\
\hline Fêmea & $2,215^{\mathrm{a}}$ & $65,67^{\mathrm{a}}$ & $34,32^{\mathrm{a}}$ & $16,46^{\mathrm{a}}$ & $13,03^{\mathrm{a}}$ \\
\hline \multicolumn{6}{|l|}{ Female } \\
\hline $\mathrm{CV}(\%)$ & 25,69 & 2,23 & 4,33 & 4,67 & 16,50 \\
\hline
\end{tabular}

Médias seguidas de letras distintas, dentro de cada coluna, para sexo, diferem pelo teste $F(P \leq 0,05)$. Means followed of different letters, within a row, for Sex, are different by $F$ test $(P \leq 0,05)$.

$Q$ - Efeito quadrático do nível de Met+Cis pelo teste $F(P \leq 0,05)$. Quadratic effect of the Meth+Cys level by $F$ test $(P \leq .05)$.

$L$ - Efeito linear do nível de Met+Cis pelo teste $F(P \leq 0,05)$. Linear effect of Meth+Cys by $F$ test $(P \leq .05)$.

ns Efeito não-significativo pelo teste $F(P \geq 0,05)$. Not significant effect by $F$ test $(P \geq .05)$.

$1 \mathrm{AU}=$ ácido úrico (uric acid), $\mathrm{mg} / \mathrm{dl}$.

$\mathrm{UM}=$ umidade da carcaça (carcass moisture).

$\mathrm{MS}=$ matéria seca (dry matter).

$\mathrm{PB}=$ proteína bruta (crude protein).

$\mathrm{EE}=$ extrato etéreo (ether extract).

do para estimar a exigência de Met+Cis. Os componentes químicos da carcaça de machos considerados neste estudo apresentaram efeitos lineares $(\mathrm{P} \leq 0,05)$ em relação aos níveis crescentes de Met+Cis, com exceção do teor de proteína na carcaça $(\mathrm{P} \geq 0,05)$. Assim, à medida que se elevaram os níveis de Met+Cis na ração, maior foi o teor de umidade da carcaça (UM), seguido de decréscimo nos teores de matéria seca (MS) e extrato etéreo (EE). Dessa forma, o maior valor de Met+Cis utilizado neste experimento, $0,930 \%$, favoreceu o menor teor de gordura na carcaça de machos.
Entre sexos, os machos apresentaram menor quantidade de extrato etéreo, não proporcionando diferenças estatísticas nas demais variáveis estudadas.

O decréscimo no teor de extrato etéreo, juntamente com o comportamento indiferente no teor de proteína bruta, proporcionou aumento substancial na concentração da proteína tissular, ou seja, enquanto o menor nível de Met+Cis (0,630\%) proporcionou $26,75 \%$ PB retida na carcaça, o maior nível $(0,930 \%)$ apresentou 48,50\% PB. Esta observação está de acordo com o conceito clássico de que a maior 
deposição de proteína tissular é acompanhada com aumento no teor de água corporal.

As carcaças das fêmeas, no entanto, apresentaram efeito quadrático para o teor de extrato etéreo, enquanto nas demais variáveis não foi observado efeito $(\mathrm{P} \geq 0,05)$ dos níveis de Met+Cis estudados. A exigência estimada a partir de equações ajustadas por meio de modelos de regressão polinomial, para o teor de extrato etéreo na carcaça de fêmeas, foi $0,831 \%$ de Met+Cis. A equação de regressão para fêmeas, sobre o teor de extrato etéreo na carcaça, podem ser observadas na Tabela 6 .

Efeito dos níveis de metionina+cistina (Met+Cis) da ração sobre o desempenho dos frangos de corte no período de 43 a 56 dias de idade

Os resultados de desempenho no período de 43 a 56 dias de idade, em função dos níveis de Met+Cis da ração, estão apresentados na Tabela 7 .
Ganho de peso e consumo de ração

O aumento dos níveis de Met+Cis na ração não influenciou significativamente o ganho de peso para ambos os sexos. Isto indica que rações com $3200 \mathrm{kcal}$ EM, $17 \%$ PB e $0,560 \%$ Met+Cis atendem a exigência para maximizar o ganho de peso para machos e fêmeas. Desse modo, como rações à base de milho e farelo de soja com $17 \%$ PB já contêm $0,560 \%$ Met+Cis, não há necessidade, portanto, de suplementação de metionina sintética. No entanto, pode-se observar tendência de maior ganho de peso em ambos os sexos, quando os animais foram submetidos ao tratamento contendo $0,740 \%$ Met+Cis, apresentando acréscimo de 74,33 e 44,55 g, no ganho de peso para machos e fêmeas, respectivamente, em relação à ração contendo o menor nível de Met+Cis $(0,560 \%)$. Como era de se esperar, os machos obtiveram ganho de peso superior $(\mathrm{P} \leq 0,05)$ ao das fêmeas, assim como para variável consumo de ração.

Os machos apresentaram comportamento linear

Tabela 6 - Sumário das análises de determinação das exigências de metionina+cistina estimadas por modelo de regressão polinomial para frangos de corte no período de 22 a 42 dias de idade

Table 6 - Summary of the determination analysis of methionine+cystine requeriment calculated by polinomial regresion model for broilers from 22 to 42 days of age

\begin{tabular}{|c|c|c|c|c|c|}
\hline \multicolumn{6}{|c|}{ Regressão (Regression) } \\
\hline $\operatorname{Sexos}(\operatorname{Sex})$ & Efeito (Effect) & Ganho de peso (Body weight), g/ave & M nível & Ex. & $\mathrm{R}^{2}$ \\
\hline $\begin{array}{l}\text { Macho } \\
\text { Male }\end{array}$ & $\begin{array}{l}\text { Quadrático } \\
\text { Quadratic }\end{array}$ & $\hat{Y}=-1313,73+6627,65 X-3771,84 X^{2}$ & 0,897 & 0,879 & 0,94 \\
\hline $\begin{array}{l}\text { Fêmea } \\
\text { Female }\end{array}$ & $\begin{array}{l}\text { Linear } \\
\text { Linear }\end{array}$ & $\hat{Y}=1044,62+282,143 X$ & 0,870 & 0,930 & 0,84 \\
\hline \multicolumn{6}{|c|}{ Conversão alimentar (Feed:gain ratio) } \\
\hline $\begin{array}{l}\text { Macho } \\
\text { Male }\end{array}$ & $\begin{array}{l}\text { Quadrático } \\
\text { Quadratic }\end{array}$ & $\hat{Y}=7,11069-11,5746 X+6,4590 X^{2}$ & 0,930 & 0,896 & 0,95 \\
\hline $\begin{array}{l}\text { Fêmea } \\
\text { Female }\end{array}$ & $\begin{array}{l}\text { Quadrático } \\
\text { Quadratic }\end{array}$ & $\hat{Y}=6,29213-9,90434 X+5,78266 X 2$ & 0,810 & 0,856 & 0,91 \\
\hline \multicolumn{6}{|c|}{ Rendimento de carcaça (Carcass yield) } \\
\hline $\begin{array}{l}\text { Machos } \\
\text { Male }\end{array}$ & $\begin{array}{l}\text { Quadrático } \\
\text { Quadratic }\end{array}$ & $\hat{Y}=37,7684+65,3519 X-40,1381 X^{2}$ & 0,690 & 0,814 & 0,42 \\
\hline $\begin{array}{l}\text { Fêmea } \\
\text { Female }\end{array}$ & $\begin{array}{l}\text { Linear } \\
\text { Linear }\end{array}$ & $\hat{Y}=61,9781+3,37010 X$ & 0,930 & 0,930 & 0,50 \\
\hline \multicolumn{6}{|c|}{ Rendimento de peito (Breast yield) } \\
\hline $\begin{array}{l}\text { Macho } \\
\text { Male }\end{array}$ & $\begin{array}{l}\text { Quadrático } \\
\text { Quadratic }\end{array}$ & $\hat{\mathrm{Y}}=10,2849+48,2887 \mathrm{X}-29,3838 \mathrm{X}^{2}$ & 0,690 & 0,822 & 0,40 \\
\hline $\begin{array}{l}\text { Fêmea } \\
\text { Female }\end{array}$ & $\begin{array}{c}\text { Quadrático } \\
\text { Quadratic }\end{array}$ & $\hat{Y}=9,84453+51,3332 X-31,0019 X^{2}$ & 0,750 & 0,828 & 0,94 \\
\hline \multicolumn{6}{|c|}{ Extrato etéreo (Ether extract) } \\
\hline $\begin{array}{l}\text { Machos } \\
\text { Male }\end{array}$ & $\begin{array}{l}\text { Linear } \\
\text { Linear }\end{array}$ & $\hat{\mathrm{Y}}=24,9656-17,8396 \mathrm{X}$ & 0,870 & 0,930 & 0,65 \\
\hline $\begin{array}{l}\text { Fêmea } \\
\text { Female }\end{array}$ & $\begin{array}{l}\text { Quadrático } \\
\text { Quadratic }\end{array}$ & $\hat{Y}=128,232-282,485 X+169,872 X^{2}$ & 0,740 & 0,831 & 0,89 \\
\hline
\end{tabular}


$(\mathrm{P} \leq 0,05)$ para consumo de ração, diminuindo, portanto, à medida que se elevou o nível de Met+Cis na ração. As fêmeas, entretanto, não apresentaram diferença $(P \geq 0,05)$ sobre o consumo de ração em quaisquer níveis testados.

\section{Conversão alimentar}

Os níveis de Met+Cis influenciaram quadraticamente $(\mathrm{P} \leq 0,05)$ a conversão alimentar para machos, entretanto, no caso das fêmeas, os níveis de Met+Cis sobre a conversão alimentar apresentaram efeito linear decrescente, ou seja, houve melhora na conversão alimentar, à medida que se elevaram os níveis de Met+Cis na ração, mostrando que os níveis utilizados não foram suficientes para estimar estatisticamente o nível ótimo de Met+Cis para esta variável, o que leva ao entendimento de que, no mínimo, $0,860 \%$ Met+Cis deve ser incluído na ração de fêmeas. Este resultado é contraditório ao obtido por GRABER et al. (1971), os quais encontraram 0,650\% Met+Cis para fêmeas na fase de 5 a 8 semanas de idade. As análises não constataram diferenças significativas entre os sexos na conversão alimentar para essa fase. Resultado semelhante foi encontrado por SILVA et al. (1984), entretanto, RESENDE et al. (1982) constataram melhor conversão alimentar para machos, em relação às fêmeas, com o aumento de Met+Cis na ração para ambiente considerado normal e quente.

As estimativas de exigência de Met+Cis foram feitas a partir de equações ajustadas, por meio de modelos de regressão para ambos os sexos, as quais estão apresentadas na Tabela 8 . A exigência estimada para conversão alimentar de machos foi de $0,764 \%$ Met+Cis. Na fase de acabamento, o critério adotado para estabelecer a exigência nutricional de Met+Cis parece ser apenas a conversão alimentar, uma vez que a variável dependente ganho de peso não foi afetada significativamente pelos níveis estudados. Isso pode ser observado nos trabalhos realizados por RESENDE et al. (1982), que estimaram 0,590\% Met+Cis, em função da conversão alimentar, e SILVA et al. (1984), por meio da mesma variável, que estimou $0,670 \%$ Met+Cis. ROSTAGNO et al. (1992) recomendam $0,682 \%$ Met+Cis para aves recebendo ração contendo $3100 \mathrm{kcal} \mathrm{EM} / \mathrm{kg}$ e 17,73\% PB. Desse modo, pode-se observar que a literatura mostra valores inferiores aos obtidos neste experimento, os quais podem ter sido influenciados pelo ambiente e principalmente pelas marcas atuais de frangos de corte.

Efeito dos níveis de metionina+cistina (Met+Cis) da ração sobre o rendimento de carcaça eviscerada e a gordura abdominal aos 56 dias de idade

Tabela 7 - Desempenho de frangos de corte submetidos a diferentes níveis de metionina+cistina de 43 a 56 dias

Table 7 - Performance of broilers submitted to different methionine + cystine levels from 43 to 56 days

\begin{tabular}{|c|c|c|c|c|c|c|}
\hline \multirow[t]{2}{*}{$\begin{array}{l}\text { Metionina+Cistina }(\%) \\
\text { Methionine }+ \text { Cystine }\end{array}$} & \multicolumn{2}{|c|}{$\begin{array}{c}\text { Ganho de peso }(\mathrm{g}) \\
\text { Feedintake }\end{array}$} & \multicolumn{2}{|c|}{$\begin{array}{l}\text { Consumo de ração }(\mathrm{g} / \mathrm{g}) \\
\text { Feed gain ratio } \\
\end{array}$} & \multicolumn{2}{|c|}{$\begin{array}{c}\text { Conversão alimentar }(\%) \\
\text { Methionine }+ \text { Cystine }\end{array}$} \\
\hline & $\begin{array}{l}\text { Macho } \\
\text { Male }\end{array}$ & $\begin{array}{l}\text { Fêmea } \\
\text { Female }\end{array}$ & $\begin{array}{c}\text { Macho } \\
\text { Male }\end{array}$ & $\begin{array}{l}\text { Fêmea } \\
\text { Female }\end{array}$ & $\begin{array}{c}\text { Macho } \\
\text { Male }\end{array}$ & $\begin{array}{l}\text { Female } \\
\text { Female }\end{array}$ \\
\hline 0,560 & 961,00 & 739,17 & 2302,67 & 1760,11 & 2,752 & 2,832 \\
\hline 0,620 & 995,00 & 762,33 & 2283,00 & 1713,56 & 2,654 & 2,685 \\
\hline 0,680 & 1018,00 & 777,67 & 2225,67 & 1754,00 & 2,520 & 2,686 \\
\hline 0,740 & 1035,33 & 783,67 & 2191,78 & 1726,00 & 2,439 & 2,634 \\
\hline 0,800 & 1007,17 & 767,00 & 2147,50 & 1636,44 & 2,469 & 2,575 \\
\hline 0,860 & 1003,00 & 768,67 & 2199,50 & 1736,28 & 2,538 & 2,597 \\
\hline Met+Cis (\%) & $\mathrm{ns}$ & $\mathrm{ns}$ & $\mathrm{L}$ & $\mathrm{ns}$ & $\mathrm{Q}$ & $\mathrm{L}$ \\
\hline$M e t+C y s$ & & & & & & \\
\hline Exigência estimada & - & - & - & - & 0,764 & - \\
\hline $\begin{array}{l}\text { Estimated requirement } \\
\text { Médias dos sexos }\end{array}$ & $1003,25^{\mathrm{a}}$ & $766,17^{b}$ & $2225,02^{\mathrm{a}}$ & $1719,40^{b}$ & $2,562^{\mathrm{a}}$ & $2,668^{a}$ \\
\hline $\begin{array}{l}\text { Sex means } \\
\text { CV }(\%)\end{array}$ & \multicolumn{2}{|c|}{6,07} & \multicolumn{2}{|c|}{5,30} & \multicolumn{2}{|c|}{4,67} \\
\hline
\end{tabular}

Médias seguidas de letras distintas, dentro de cada linha, para sexo, diferem pelo teste $\mathrm{F}(\mathrm{P} \leq 0,05)$.

Means followed of different letters, within each line, for sex, are different by $F$ test $(P \leq .05)$.

$\mathrm{Q}$ - Efeito quadrático do nível de Met+Cis pelo teste $\mathrm{F}(\mathrm{P} \leq 0,05)$.

Quadratic effect of the Meth+Cys level by F test $(P \leq .05)$.

L- Efeito linear do nível de Met+Cis pelo teste $F(P \leq 0,05)$.

Linear effect of Meth+Cys level by $F$ test $(P \leq .05)$.

ns Efeito não-significativo pelo teste $F(P \geq 0,05)$.

Not significant effect by $F$ test $(P \geq .05)$. 
Os resultados de rendimento de carcaça eviscerada e gordura abdominal aos 56 dias de idade, em função dos níveis de Met+Cis na ração, estão apresentados na Tabela 9.

As características de rendimento de carcaça e gordura abdominal, para ambos os sexos, não foram influenciadas $(\mathrm{P} \geq 0,05)$ pelos níveis de Met+Cis estudados, indicando novamente que rações à base de milho e farelo de soja contendo $17 \%$ PB e $0,560 \%$ Met+Cis suprem as necessidades para o máximo desenvolvimento das características analisadas.

Apesar de os machos terem apresentado rendi- mento de perna superior $(\mathrm{P} \leq 0,05)$ ao das fêmeas, o rendimento de carcaça não foi influenciado significativamente pelo sexo. Os rendimentos de cortes, principalmente as partes consideradas nobres, como peito e filé de peito, foram superiores $(\mathrm{P} \leq 0,05)$ para as fêmeas em relação aos machos.

Como o rendimento de gordura abdominal não sofreu influência dos níveis de Met+Cis, a superioridade dos machos em proporcionar menor rendimento de gordura na regiãoperianal, na moela eno proventrículo, em relação às fêmeas, deve-se ao maior peso de carcaça.

Tabela 8 - Sumário das análises de determinação das exigências de metionina+cistina estimadas por modelo de regressão polinomial para frangos de corte no período de 43 a 56 dias de idade

Table 8 - Summary of determination analyses of methinine+cystine requeriments calculated by plinomial regresion model for broilers from 43 to 56 days of age

\begin{tabular}{|c|c|c|c|c|c|}
\hline & & $\begin{array}{l}\text { ações de regressão (Regresion equation) } \\
\text { Conversão alimentar (Feed:gain ratio) }\end{array}$ & M nível & Ex. & $\mathrm{R}^{2}$ \\
\hline Machos & Quadrático & $\hat{\mathrm{Y}}=6,79512-11,3310 \mathrm{X}+7,40770 \mathrm{X} 2$ & 0,740 & 0,764 & $0,96^{*}$ \\
\hline Male & Quadratic & & & & \\
\hline Fêmeas & Linear & $\hat{Y}=3,19564-0,742784 X$ & 0,800 & 0,860 & $0,82 *$ \\
\hline Female & Linear & & & & \\
\hline
\end{tabular}

Tabela 9 - Efeito de diferentes níveis de Met+Cis da ração sobre rendimento de carcaça eviscerada, cortes e gordura abdominal de frangos de corte aos 56 dias de idade

Table 9 - Effect of different level of Meth+Cys of the diet on eviscerated carcass yield, cuts and abdominal fat of broilers at 56 days of age

\begin{tabular}{|c|c|c|c|c|c|c|c|c|c|c|}
\hline \multirow[b]{3}{*}{$\begin{array}{l}\text { Met+Cis (\%) } \\
\text { Meth+Cys }\end{array}$} & \multicolumn{10}{|c|}{ Rendimento (Yield), \% } \\
\hline & \multicolumn{2}{|c|}{$\begin{array}{l}\text { Carcaça } \\
\text { Carcass }\end{array}$} & \multicolumn{2}{|c|}{$\begin{array}{l}\text { Peito } \\
\text { Breast }\end{array}$} & \multicolumn{2}{|c|}{$\begin{array}{c}\text { Filé de peito } \\
\text { Breast fillet }\end{array}$} & \multicolumn{2}{|c|}{$\begin{array}{l}\text { Pernas } \\
\text { Legs }\end{array}$} & \multicolumn{2}{|c|}{$\begin{array}{c}\text { Gordura } \\
\text { Fat }\end{array}$} \\
\hline & $\begin{array}{c}\text { Macho } \\
\text { Male }\end{array}$ & $\begin{array}{l}\text { Fêmea } \\
\text { Female }\end{array}$ & $\begin{array}{c}\text { Macho } \\
\text { Male }\end{array}$ & $\begin{array}{l}\text { Fêmea } \\
\text { Female }\end{array}$ & $\begin{array}{c}\text { Macho } \\
\text { Male }\end{array}$ & $\begin{array}{l}\text { Fêmea } \\
\text { Female }\end{array}$ & $\begin{array}{c}\text { Macho } \\
\text { Male }\end{array}$ & $\begin{array}{l}\text { Fêmea } \\
\text { Female }\end{array}$ & $\begin{array}{c}\text { Macho } \\
\text { Male }\end{array}$ & $\begin{array}{l}\text { Fêmea } \\
\text { Female }\end{array}$ \\
\hline 0,560 & 70,06 & 69,61 & 29,66 & 30,47 & 20,72 & 21,04 & 30,71 & 28,63 & 3,191 & 3,640 \\
\hline 0,620 & 70,35 & 69,95 & 30,38 & 30,73 & 21,54 & 21,77 & 30,29 & 28,97 & 3,021 & 3,566 \\
\hline 0,680 & 69,88 & 70,37 & 30,04 & 30,88 & 21,57 & 21,57 & 30,15 & 28,93 & 2,808 & 3,790 \\
\hline 0,740 & 69,40 & 69,12 & 28,54 & 31,47 & 21,13 & 21,64 & 30,40 & 29,14 & 2,907 & 3,585 \\
\hline 0,800 & 71,18 & 69,93 & 25,55 & 30,95 & 20,54 & 22,15 & 29,40 & 29,00 & 2,896 & 3,418 \\
\hline 0,860 & 70,74 & 71,83 & 30,06 & 30,52 & 21,26 & 21,42 & 30,61 & 28,54 & 2,961 & 3,523 \\
\hline$\% \mathrm{Met}+\mathrm{Cis}$ & $\mathrm{ns}$ & $\mathrm{ns}$ & $\mathrm{ns}$ & $\mathrm{ns}$ & $\mathrm{ns}$ & $\mathrm{ns}$ & $\mathrm{ns}$ & $\mathrm{ns}$ & $\mathrm{ns}$ & $\mathrm{ns}$ \\
\hline Exigência & - & - & - & - & - & - & - & - & - & - \\
\hline $\begin{array}{l}\text { Requirement } \\
\text { Médias }\end{array}$ & $70,27^{\mathrm{a}}$ & $70,14^{\mathrm{a}}$ & $29,71^{b}$ & $30,84^{\mathrm{a}}$ & $21,13^{\mathrm{b}}$ & $21,60^{\mathrm{a}}$ & $30,26^{\mathrm{a}}$ & $28,87^{b}$ & $2,964^{\mathrm{b}}$ & $3,587^{\mathrm{a}}$ \\
\hline $\begin{array}{l}\text { Means } \\
\mathrm{CV}(\%)\end{array}$ & \multicolumn{2}{|c|}{3,14} & \multicolumn{2}{|c|}{5,19} & \multicolumn{2}{|c|}{4,53} & \multicolumn{2}{|c|}{4,00} & \multicolumn{2}{|c|}{16,14} \\
\hline
\end{tabular}

Médias seguidas de letras distintas, dentro de cada linha, para sexo, diferem pelo teste $F(P \leq 0,05)$.

Means followed of different letters, within each line, for sex, are different by $F$ test $(P \leq 0,05)$.

Q- Efeito quadrático do nível de Met+Cis pelo teste $\mathrm{F}(\mathrm{P} \leq 0,05)$.

Quadratic effect of the Met+Cys level by $F$ test $(P \leq 0,05)$.

L- Efeito linear do nível de Met+Cis pelo teste $\mathrm{F}(\mathrm{P} \leq 0,05)$

Linear effect of Met+Cys level by $F$ test $(P \leq 0,05)$.

ns Efeito não-significativo pelo teste $F(P \geq 0,05)$.

Not significant effect by $F$ test $(P \geq 0,05)$. 
Efeito dos níveis de metionina+cistina (Met+Cis) sobre composição a química da carcaça eviscerada e a concentração de ácido úrico no plasma sangüineo de frangos de corte aos 56 dias de idade

A composição química da carcaça eviscerada e a concentração de ácido úrico no plasma sangüíneo de frangos de corte aos 56 dias de idade, em função do nível de Met+Cis, estão apresentadas na Tabela 10.

As concentrações de ácido úrico no plasma sangüíneo de machos foi menor $(\mathrm{P} \leq 0,05)$ quando comparado ao das fêmeas, apresentando redução de $16,16 \%$. Isto demonstra que as rações experimentais desencadearam maior desequilíbrio nutricional, no organismo das fêmeas, levando-as a desaminar os aminoácidos em excesso, não sendo então aproveitados para a síntese de proteína corporal, mas sim para o metabolismo energético e conseqüente deposição de gordura corporal. Em decorrência disso, as fêmeas não apresentaram ponto de mínimo para a conversão alimentar na fase final de criação, não atingindo, com maior precisão, sua necessidade de Met+Cis, e a adoção de uma fase final de criação para as fêmeas semelhantes aos machos torna-se nutricionalmente dispendiosa. No entanto, os níveis de Met+Cis não

Tabela 10 - Efeito de diferentes níveis de Met+Cis sobre composição química da carcaça e concentração de ácido úrico em frangos de corte aos 56 dias de idade ${ }^{1}$

Table 10 - Effect of different Met+Cys levels on the chemical composition of the carcass and uric acid concentration in broilers at 56 days of age

\begin{tabular}{|c|c|c|c|c|c|}
\hline \multirow[b]{2}{*}{ Met+Cis $($ Meth+Cys), \% } & \multicolumn{5}{|c|}{ Macho (Male) } \\
\hline & $\mathrm{AU}$ & UM & MS & PB & $\mathrm{EE}$ \\
\hline$\overline{0,560}$ & 2,441 & 64,08 & 35,91 & 16,10 & 21,44 \\
\hline 0,620 & 2,571 & 65,08 & 34,92 & 17,04 & 19,63 \\
\hline 0,680 & 2,610 & 66,21 & 33,78 & 16,40 & 17,94 \\
\hline 0,740 & 2,407 & 65,68 & 34,32 & 17,07 & 17,86 \\
\hline 0,800 & 2,391 & 66,13 & 33,87 & 16,89 & 16,16 \\
\hline 0,860 & 2,905 & 67,51 & 32,49 & 17,09 & 14,87 \\
\hline \multirow[t]{2}{*}{ Met+Cis $($ Met + Cys $), \%$} & $\mathrm{~ns}$ & $\mathrm{~L}$ & $\mathrm{~L}$ & $\mathrm{~L}$ & $\mathrm{~L}$ \\
\hline & \multicolumn{5}{|c|}{ Fêmea (Female) } \\
\hline 0,560 & 2,828 & 64,42 & 35,58 & 15,74 & 21,71 \\
\hline 0,620 & 3,263 & 64,36 & 35,63 & 15,93 & 21,27 \\
\hline 0,680 & 4,073 & 63,21 & 36,79 & 16,31 & 23,45 \\
\hline 0,740 & 1,994 & 63,49 & 36,51 & 16,19 & 21,46 \\
\hline 0,800 & 3,049 & 64,41 & 33,87 & 16,77 & 19,12 \\
\hline 0,860 & 3,249 & 64,19 & 35,80 & 15,96 & 19,78 \\
\hline Met+Cis $(M e t+C y s), \%$ & $\mathrm{~ns}$ & $\mathrm{~ns}$ & $\mathrm{~ns}$ & $\mathrm{~ns}$ & $\mathrm{~ns}$ \\
\hline \multirow{2}{*}{\multicolumn{6}{|c|}{$\begin{array}{l}\text { Exigências estimadas } \\
\text { Estimated requirements }\end{array}$}} \\
\hline & & & & & \\
\hline Macho & - & - & - & - & - \\
\hline Male & & & & & \\
\hline Fêmea & - & - & - & - & - \\
\hline Female & & & & & \\
\hline \multicolumn{6}{|l|}{ Médias dos sexos } \\
\hline \multicolumn{6}{|l|}{ Sex means } \\
\hline Macho & $2,560^{\mathrm{b}}$ & $65,78^{a}$ & $34,21^{\mathrm{b}}$ & $16,76^{\mathrm{a}}$ & $17,98^{b}$ \\
\hline Male & & & & & \\
\hline Fêmea & $3,070^{\mathrm{a}}$ & $64,01^{\mathrm{b}}$ & $35,98^{a}$ & $16,15^{\mathrm{b}}$ & $21,13^{\mathrm{a}}$ \\
\hline Female & & & & & \\
\hline CV (\%) & 24,14 & 2,58 & 4,78 & 4,12 & 16,37 \\
\hline
\end{tabular}

Médias seguidas de letras distintas, dentro de cada coluna, para sexo, diferem pelo teste $F(P \leq 0,05)$. Means followed of different letters, within each row, for sex, are different by $F$ test $(P \leq .05)$.

$Q$ - Efeito quadrático do nível de Met+Cis pelo teste $F(P \leq 0,05)$.

Quadratic effect of the Met+Cys level by $F$ test $(P \leq .05)$.

$\mathrm{L}$ - Efeito linear do nível de Met+Cis pelo teste $\mathrm{F}(\mathrm{P} \leq 0,05)$.

Linear effect of Met+Cys by $F$ test (PS.05).

ns Efeito não-significativo pelo teste $F(P \geq 0,05)$.

Not significant effect by $F$ test $(P \geq .05)$.

1- $\mathrm{AU}=$ ácido úrico (uric acid), $\mathrm{mg} / \mathrm{dL}$.

$\mathrm{UM}=$ umidade da carcaça (carcass moisture).

$\mathrm{MS}=$ matéria seca (dry matter).

$\mathrm{PB}=$ proteína bruta (crude protein).

$\mathrm{EE}=$ extrato etéreo (ether extract). 
influenciaram de forma significativa a concentração de ácido úrico em ambos os sexos. Resultados semelhantes foram encontrados por RESENDE et al. (1980). O elevado coeficiente de variação (CV) relativo a esta variável torna-se, portanto, inadequado para estimar a exigência de Met+Cis.

Apesar de a composição química da carcaça de fêmeas não apresentar efeito significativo pelos níveis de Met+Cis da ração, os machos, entretanto, apresentaram efeito linear $(\mathrm{P} \leq 0,05)$. Assim, à medida que se aumentaram os níveis de Met+Cis na ração, maior foi o teor de umidade de carcaça (UM) e proteína bruta $(\mathrm{PB})$, seguido de decréscimo nos teores de matéria seca (MS) e extrato etéreo (EE).

Os teores de extrato etéreo presentes na carcaça das aves, na fase de acabamento, são consideravelmente maiores que no período de crescimento, mostrando claramente o efeito da idade sobre a deposição de gordura em animais submetidos à alimentação $a d$ libitum. Menor teor de extrato etéreo foi encontrado na carcaça de machos, à medida que se aumentaram os níveis de Met+Cis na ração, observando-se, então, efeito positivo em função dos níveis adotados. Dessa forma, o maior valor de Met+Cis utilizado neste experimento, $0,860 \%$, é considerado o nível mínimo para favorecer maior deposição proteína e menor gordura na carcaça de machos. As fêmeas, entretanto, por apresentarem comportamento indiferente aos níveis de Met+Cis utilizados, requerem a exigência para atender à porcentagem satisfatória de proteína bruta, extrato etéreo, matéria seca e umidade na carcaça, $0,560 \%$, a qual é atendida com fornecimento de ração à base de milho e farelo de soja contendo $17 \%$ PB, sem suplementação de metionina sintética.

\section{Conclusões}

$\mathrm{Na}$ fase de crescimento ( 22 a 42 dias de idade) com base no ganho de peso e na conversão alimentar, sugere-se a recomendação mínima de $0,896 \%$ para machos ou $0,284 \%$ metionina+cistina total/Mcal deEM.

Com base na conversão alimentar, sugere-se a recomendação mínima de $0,856 \%$ para as fêmeas, ou $0,272 \%$ metionina+cistina total/Mcal de EM.

Para a fase de acabamento (43 a 56 dias de idade), as análises estatísticas para a conversão alimentar, sugere-se utilizar $0,764 \%$ metionina+cistina total para machos, ou 0,239\% metionina+cistina total/Mcal de EM. Todavia, sugere-se, para fêmeas, adotar $0,740 \%$ metionina+cistina total, por apresentar o melhor valor biológico para ganho de peso dentre os níveis testados, ou $0,231 \%$ metionina+cistina total/Mcal de EM.

\section{Referências Bibliográficas}

AJANG, O.A., PROJONO, S., SMITH, W.K. 1993. Effect of dietary protein level on growth and body composition of fast and slow feathering broiler chickens. Br. Poult. Sci., 37:73-91.

AVES e OVOS. 1995. Tendências de consumo, 11(4):10.

CAREN, L.B., HILL, F.W. 1961. Effect of methionine deficiency on the utilization of energy by the chick. J. Nut., 74:185-190.

CARTE, I. Evolução genética dos frangos até o século XXI. In: CONGRESSO BRASILEIRO DE AVICULTURA E EXPOSIÇÃONACIONAL DE AVICULTURA, 13, Brasília, DF. Anais... Brasília: UBA, p.34-37, 1993.

COLNAGO, G.L. Fatores que influenciam as exigências nutricionais de aves. In: SIMPÓSIO INTERNACIONAL SOBRE EXIGÊNCIAS NUTRICIONAIS DE AVES E SUÍNOS, 1996, Viçosa, MG. Anais ... Viçosa: DZO, UFV, 1996, p.345-360, 1996.

GRABER, H.G., SCOTT, H.M., BACKER, D.H. 1971. Sulfur amino acid nutrition of the growing chick: Effect of age on the dietary methionine requirement. Poult. Sci., 50:854-858.

HAN, Y., SUZUKI, H., PARSONS, C.M. et al. 1992. Amino acid fortification of a low-protein corn and soybean meal diet for chicks. Poult. Sci., 71:1168-1178.

JENSEN, L.S., WYATT, C.L., FANCHER, B.I. 1989. Sulfur amino acid requirement of broiler chickens from 3 to 6 weeks of age. Poult. Sci., 68:163-168.

PESTI, G.M., LECLERCQ, B., CHAGNEAU, A.M. et al. 1996. Effect of the naked neck ( $\mathrm{Na}$ ) gene on the sulfur-containing amino acid requirements of broilers. Poult. Sci., 75:375-380.

RESENDE, J.A.A., ROSTAGNO, H.S., FONSECA, J.B. et al. 1980. Níveis de proteína, aminoácidos sulfurosos e lisina na ração de frangos, submetidos a regime de alta temperatura. II. Fase de acabamento. R. Soc. Bras. Zootec., 9:125-141.

ROSTAGNO, H.S., BARBARINO, P., BARBOZA, W.A. Exigências nutricionais das aves determinadas no Brasil. SIMPÓSIO INTERNACIONAL SOBRE EXIGÊNCIAS NUTRICIONAIS DE AVES E SUÍNOS, Viçosa, MG, 1996. Anais... Viçosa: UFV, p.361-388, 1996.

ROSTAGNO, H.S., SILVA, D.J., COSTA, P.M.A. et al. 1992. Composição de alimentos e exigências nutricionais de aves e suínos (Tabelas Brasileiras). Viçosa, MG: Imprensa Universitária, 4.ed. 59p.

SAEG - Sistema para Análise Estatísticas e Genéticas. 1997. versão 7.0. Viçosa: Fundação Arthur Bernardes.

SCHUTTE, J.B., PACK, M. 1995a. Effects of dietary sulfurcontaining amino acids on performance and breast meat deposition of broiler chicks during the growing and finishing phases. Poult. Sci., 36:747-762.

SCHUTTE, J.B., PACK, M. 1995b. Sulfur amino acid requirement of broilers chicken from fourteen to thirty-eight days of age. 1. Performance and carcass yield. Poult. Sci., 74:480-487.

SCHERMANN, G. N., BELLAVER, C. Estado da arte e a perspectiva para pesquisa futura em nutrição de aves. In: REUNIÃO ANUAL DA SOCIEDADE BRASILEIRA DE ZOOTECNIA, 32, Brasília, DF, 1995. Anais... Viçosa: SBZ, 1995. p.465-473.

SEKIS, S.S., SCOTT, M.L., NESHEIM, M.C. 1975. The effect of methionine deficiency on body weight, food and energy utilization in the chick. Poult. Sci., 54:1184-1188.

SILVA, S.H.M. Níveis de aminoácidos em ração de frangos de corte. Viçosa, MG: UFV, 1996. 67p. Dissertação (Mestrado em Zootecnia) - Universidade Federal de Viçosa, 1996.

SILVA, P.C., ROSTAGNO, H.S., FONSECA, J.B. et al. 1984. Níveis dietéticos de lisina e aminoácidos sulfurosos para frangos de corte, na fase de acabamento. R. Soc. Bras. Zootec., 13:274-284.

WHEELER, K.B., LATSHAW, J.D. 1981. Sulfur amino acid requirements and interactions in broilers during two growth periods. Poult. Sci., 60:228-236.

Recebido em: 30/10/98 Aceito em: 27/08/99 